\title{
KEMAMPUAN BERPIKIR DIVERGEN DITINJAU DARI MATH ANXIETY DAN GENDER PADA PEMBELAJARAN MATEMATIKA
}

\author{
Ghazian Nurin Izzati ${ }^{1)}$ \\ Stevanus Budi Waluya ${ }^{2)}$ \\ Zaenuri Mastur ${ }^{3)}$ \\ 1), 2), 3) Program Studi Pendidikan Matematika, Universitas Negeri Semarang \\ Email: ${ }^{1)}$ asdfghazian@student.unnes.ac.id
}

\begin{abstract}
ABSTRAK
Kemampuan berpikir divergen dalam pembelajaran matematika dapat ditinjau melalui gender yang mempengaruhi pola pikir seseorang dan pola pikir dalam menghadapi math anxiety. Artikel ini memiliki tujuan untuk mendeskripsikan mengenai kemampuan berpikir divergen ditinjau dari math anxiety dan gender pada pembelajaran matematika. Penelitian dengan metode literature review. Pencarian database yanga digunakan meliputi Google Scholar, Scopus, Web of Science. Adapun banyak artikel yang dikaji yaitu 15 artikel yang bersumber dari jurnal nasional maupun jurnal internasional. Hasil kajian diperoleh bahwa komponen flexibility di dalam kemampuan berpikir divergen perlu ditingkatkan dengan merancang pemikiran siswa pada proses pembelajaran matematika agar dapat berpikir secara meluas dan kreatif serta mengontrol math anxiety siswa dalam belajar, math anxiety dapat berpengaruh dalam bermatematika karena setiap individu memiliki tingkat kecemasan yang berbeda, dan perempuan mempunyai math anxiety yang lebih tinggi daripada laki-laki. Gender berpengaruh dalam bermatematika karena perempuan dan laki-laki mengontrol pembelajaran matematika dengan kecakapan yang berbeda oleh masing-masing anak melalui motivasi yang diberikan sesuai dengan gender.
\end{abstract}

Kata kunci: Berpikir Divergen, Math Anxiety, Gender, Pendidikan, Matematika.

\begin{abstract}
Divergent thinking skills in math learning can be reviewed through gender that affect a person's mindset and mindset in the face of math anxiety. This article aims to describe about the divergent thinking ability reviewed from math anxiety and gender in mathematics learning. Research with literature review method. Search databases used include Google Scholar, Scopus, Web of Science. The many articles studied are 15 articles sourced from national journals and international journals. The results of the article is the flexibility component in divergent thinking ability needs to be improved by designing students' thinking on the mathematical learning process in order to think widely and creatively and control students' math anxiety in learning, math anxiety can have an effect in mathematics because each individual has a different level of anxiety, and girl have higher math anxiety than boy. Gender is influential in mathematics because
\end{abstract}


girl and boy control math learning with different skills by each child through motivation given according to gender.

Keywords: Divergent Thinking, Math Anxiety, Gender, Education, Mathematics.

\section{PENDAHULUAN}

Pada dasarnya, peserta didik memiliki pemikiran yang meluas pada setiap mata pelajaran terutama mata pelajaran matematika, peserta didik memiliki imajinasi atau pola pikir yang berbeda-beda untuk menanggapi materi atau hal yang disampaikan, peserta didik memiliki pemikiran masing-masing untuk memandang soal atau materi yang dijelaskan di depan kelas dengan berpikir secara meluas atau berpikir divergen. Berpikir secara divergen atau secara meluas merupakan salah satu bagian dari berpikir kreatif dalam bermatematika. Divergent thinking ability is an important element and the part of creativity, Orangorang kreatif sering memiliki banyak ide. Kemampuan untuk menghasilkan sejumlah besar ide tentang suatu topik adalah salah satu aspek pemikiran kreatif (Unal \& Demir, 2009). Berpikir adalah proses divergen dengan menggunakan berbagai cara untuk mendapatkan hasil atau tujuan, di samping itu, bahwa dengan memiliki beberapa pilihan, siswa memiliki kemungkinan untuk membuat atau merancang strategi baru dan menjadi lebih efisien (Sosa, 2018).

Pada kehidupan, matematika memiliki peran yang penting secara eksplisit dan implisit. Seseorang akan berpikir secara terstruktur, faktual, rasional, kritis, serta dapat meningkatkan daya kreativitas melalui matematika, namun banyak peserta didik yang memiliki firasat buruk, muncul rasa takut,

sulit berkonsentrasi hingga bingung dengan kegunaan langsung materi yang dipaparkan pada pelajaran matematika, ada beberapa alasan yang kerap disampaikan mengenai ketakutan peserta didik dalam belajar matematika, di antaranya adalah karena matematika berbentuk abstrak, banyak rumus, pengaruh persepsi umum, matematika diperuntukkan kepada anak yang pandai (Sriyanto, 2007) atau yang biasa disebut dengan math anxiety. Pada dasarnya, Math anxiety didefinisikan sebagai reaksi perilaku negatif dalam situasi yang mencakup ekspresi kemampuan belajar matematika atau evaluasi pengetahuan matematika, di mana itu menyebabkan stres, tidak nyaman dan penghindaran (Ashcraft, 2002). Ketika membahas kekuatan hubungan antara math anxiety dan pencapaian matematika, penelitian menunjukkan bahwa korelasi ini dapat dijelaskan dalam hal koefisien korelasi rendah hingga sedang (Ho et al., 2000).

Beberapa

mengungkapkan bahwa gender mempengaruhi pola pikir seseorang dan pola pikir dalam menghadapi math anxiety, Keyakinan positif bahwa matematika adalah cair dan masuk akal telah terbukti berkontribusi pada tingkat math anxiety yang lebih rendah dan prestasi matematika yang lebih tinggi (Upadyaya \& Eccles, 2014). Menurut Susento (2014) setiap gender memiliki padangan yang berbeda pada matematika pandangan yang berbeda terhadap matematika, adanya perbedaan jenis

70 Kemampuan Berpikir Divergen Ditinjau Dari Math Anxiety Dan Gender Pada Pembelajaran Matematika G. N. Izzati - S.B Waluya-Zaenuri 
kelamin tidak hanya berlaku pada kecakapan bermatematika, tetapi juga pada langkah menyerap materi matematika, sedangkan menurut Keitel (1998), "Dimensi gender, sosial dan budaya memiliki interaksi yang kuat dalam konsep bermatematika...," gender memiliki pengaruh yang cuukp besar pada masa sekolah dasar, oleh karena itu hubungan math anxiety dan gender dalam berpikir divergen yang mempengaruhi kreativitas matematika diharapkan dapat diperhatikan dengan khusus dalam pembelajaran matematika (Brandon et al, 1985).

Literature review ini meneliti kemampuan berpikir divergen dalam pembelajaran matematika, selain itu, didasarkan pada bagaimana math anxiety dan gender dalam berpikir divergen ketika siswa menghadapi pembelajaran matematika. Literature review ini bertujuan untuk menganalisis kemampuan berpikir divergen berdasarkan math anxiety dan gender pada pembelajaran matematika.

\section{METODE PENELITIAN}

\section{Literature Search}

Metode yang digunakan adalah literature review, dengan melakukan research artikel pada database jurnal dan tesis, research dilakukan melalui internet, dan meninjau ulang artikel yang diperoleh. Pencarian database yang digunakan meliputi Google Scholar, Scopus, Web of Science, ProQuest, menggunakan beberapa kata kunci dalam pencarian, yakni "divergent thinking on mathematics (math)", "divergent thinking ability on mathematics", "mathematics anxiety, "math anxiety" dan "math anxiety and gender on mathematics (math) learning" terdapat 27 artikel telah didapatkan dan 15 artikel yang dilanjutkan dengan analisis melalui analisis pada tujuan, kesesuaian yang ada pada topik, dan metode yang digunakan pada penelitian. Kemudian, pencarian disempurnakan mengikuti kriteria inklusi.

\section{Kriteria Inklusi Literatur}

Artikel-artikel tersebut disaring lebih lanjut berdasarkan kriteria berikut:

(a) Kemampuan berpikir divergen dan prestasi matematika keduanya diukur, dan hasilnya dilaporkan. Setiap studi harus memenuhi hubungan antara kemampuan berpikir divergen dan kinerja matematika; studi yang hanya mengukur kemampuan berpikir divergen atau hanya mengukur kinerja matematika dikeluarkan.

(b) Math anxiety dan gender pada pembelajaran matematika keduanya diukur dan hasilnya dilaporkan, tidak hanya membahas math anxiety atau gender saja, namun membahas hubungan keduanya dalam pembelajaran matematika.

(c) Studi harus secara eksplisit melaporkan ukuran sampel, jika penelitian tidak melaporkan ukuran sampel maka akan dikeluarkan.

\section{HASIL PENELITIAN DAN PEMBA- HASAN}

Kemampuan berpikir divergen dalam matematika

Cara berpikir setiap orang memiliki pola yang berbeda-beda, berpikir secara meluas menandakan sifat kreatif yang dimiliki oleh seseorang, 
berpikir secara meluas atau biasa disebut dengan kemampuan berpikir divergen. Kemampuan berpikir divergen pada matematika yang dimiliki peserta didik merupakan salah satu proses berpikir kreatif, peserta didik berpikir secara divergen untuk memecahkan suatu permasalahan matematika dengan menggunakan pemahaman dan konsepkonsep dasar pada matematika yang dihubungkan dengan pengalaman yang terdahulu untuk menemukan suatu konsep yang baru dan menghasilkan suatu proses berpikir kreatif, pada dasarnya seorang peserta didik memiliki kemampuan berpikir divergen namun peserta didik memiliki kecakapan yang berbeda apabila ditinjau melalui math anxiety dan gender. Menurut Guildford (1956) Kemampuan berpikir divergen berdasakan komponen berpikir divergen antara lain: fluency, flexibility, originality dan elaboration. Proses berpikir divergen merupakan aspek kreativitas yang paling khas dan tersirat dalam memikirkan ide-ide yang benarbenar baru atau merasakan masalah dengan cara yang berbeda, aspek yang membawa berbagai konsekuensi kemampuan untuk menghasilkan jawaban inovatif, misalnya, menemukan cara untuk memecahkan masalah matematika seperti yang belum pernah dipikirkan sebelumnya. Pemikiran yang berbeda adalah alat yang telah dimanipulasi dalam beberapa dekade terakhir, karena seperti yang ditunjukkan dalam dasar teoritis pada subjek, tidak ada keraguan bahwa aspek kreatif pada manusia dapat memiliki domain tertentu karena seseorang biasanya kreatif di satu bidang, tetapi tidak secara keseluruhan atau tidak berhasil mengkonsolidasikan tingkat efektivitas yang tinggi dengan cara yang homogen. Banyak peserta didik yang tidak cakap dalam menjawab soal dan hanya terpatri dengan satu cara yang dikuasai. kelemahan lainnya adalah dalam indikator fleksibel atau alternatif, siswa melihat masalah hanya dari satu perspektif, meskipun masalah matematika dapat diselesaikan dengan menggunakan perspektif yang lain (Faridah \& Ratnaningsih, 2019). Pembahasan mengenai pemikiran divergen sebagai ciptaan karakteristik mendasar, tidak seperti pendapat konvergen di mana segala sesuatu diarahkan ke satu solusi, pendapat divergen mencari yang paling beragam. Tidak ada solusi untuk situasi masalah yang dipertimbangkan dan pemikiran tersebar pada berbagai kemungkinan solusi, selain pembentukan opini yang konvergen, harus membuat ruang untuk pemikiran divergen (Kadum, 2019). Pada temuan PISA tahun 2003 di Turki, kemampuan berpikir divergen yang dimiliki peserta didik memiliki batasannya masing-masing. Terdapat hasil berbeda yang signifikan antara peserta didik yang menggunakan cara berpikir divergen (memikirkan cara-cara baru untuk mendapatkan jawaban) dan peserta didik yang tidak menggunakan cara berpikir divergen. Saat membuat perbandingan masing-masing gender, laki-laki melebihi jumlah perempuan dalam hal pemikiran divergen (pikirkan cara baru untuk mendapatkan jawabannya), prestasi matematika peserta didik dan keterampilan berpikir divergen, gender dibandingkan berdasarkan wilayah Turki (Unal \& Demir, 2009), lalu pada temuan Fauziah et al., (2020) Indikator berpikir divergen yang paling dominan 
atau paling tinggi adalah indikator kefasihan (76\%), sedangkan yang paling rendah adalah indikator elaborasi $(65.80 \%)$. Persentase perolehan rata-rata pada indikator fleksibilitas adalah $74 \%$ dan indikator orisinalitas adalah $68 \%$, perolehan hasil dari berbagai indikator dari kemampuan berpikir divergen memiliki hasil yang hampir sama pada persentase. Namun Hasil uji Torrance Test of Creative Thinking menunjukkan bahwa terdapat perbedaan signifikan pada skor kefasihan dan fleksibilitas (Hija Park, 2004), dan ditemukan bahwa $61 \%$ memiliki tingkat pemikiran divergen ratarata, dengan orisinalitas yang dominan $(\beta$ $=$, 407), maka untuk meningkatkan tingkat pemikiran divergen mereka harus fleksibel dalam berpikir dan orisinalitas (Poves et al., 2020). Pada sebuah hasil penelitian menunjukkan bahwa hasil tes matematika pada tingkat menengah tergolong baik, yaitu merumuskan lebih dari satu cara untuk menyelesaikan tes atau masalah statistik. Namun, mereka tidak dapat menjawab dengan cara mereka. Komponen yang diserap adalah kelancaran, orisinalitas, dan elaborasi (Ibnatur Husnul \& Hasanah, 2020), dan pada berbagai hasil temuan yang diperoleh dapat dilihat bahwa kemampuan berpikir divergen pada pembelajaran matematika seorang anak harus diperhatikan lebih lanjut pada indikator fleksibilitas yaitu melihat masalah dari perspektif yang berbeda, mengubah sikap untuk memecahkan masalah dan mengembangkan perspektif yang lain guna merespon masalah dengan jawaban yang serupa (Guildford, 1956). Keberagaman masalah adalah alat yang tepat untuk melatih peserta didik untuk menggunakan semua pemikiran matematika potensial. Selain itu, melalui tahapan solusi masalah yang berbeda, proses pemikiran matematika peserta didik dapat ditelusuri. (Pujiastuti et al., 2020)

\section{Math anxiety dan Gender}

Peserta didik lebih menunjukkan ketertarikan dalam melakukan eksplorasi suatu permasalahan matematika ketika diberi dorongan yang kuat oleh guru, dan membuat pemikiran yang dimiliki peserta didik cenderung bisa dipengaruhi oleh rasa cemas dalam belajar, dengan demikian, peserta didik akan memiliki basis pengetahuan matematika yang solid apabila dalam pembelajaran didorong dengan kemauan yang kuat. Aturan ini sejalan dengan bukti yang menunjukkan bahwa fondasi yang kuat dalam pengetahuan matematika bermanfaat untuk membebaskan MA (Math anxiety) dan meningkatkan kinerja matematika (Beilock and Willingham, 2014). Reaksi afektif negatif dan kekhawatiran berkontribusi secara signifikan dan negatif terhadap pencapaian matematika pada kedua gender, tetapi motivasi matematika dapat memediasi hubungan tersebut sebagian di kalangan anak perempuan, tetapi sepenuhnya di antara anak laki-laki (Milovanović, 2020). Berbagai penelitian menunjukkan bahwa gender berpengaruh pada math anxiety, beberapa penelitian menunjukkan bahwa Math anxiety lebih banyak dialami oleh perempuan, namun math anxiety yang dialami oleh individu tergantung pada lingkungan dan cara memandang matematika itu sendiri, namun hal itu tidak berlaku secara konsisten pada 
berbagai penelitian. Tingkat math anxiety yang lebih tinggi secara signifikan pada anak perempuan, dengan efek terbesar diamati pada anak perempuan kelas 2 . Temuan ini menyoroti pentingnya mempertimbangkan perbedaan gender saat mempelajari matematika (Van Mier et al., 2019) sedangkan Devine et al., (2012) menemukan bahwa tingkat Math anxiety dan Test Anxiety lebih tinggi untuk perempuan daripada laki-laki. Anak perempuan dan laki-laki menunjukkan korelasi positif antara Math anxiety dan Test Anxiety, dan Maloney et al. (2012) menemukan bahwa perempuan mungkin memiliki tingkat MA yang tinggi daripada laik-laki ketika berhadapan dengan tugastugas yang melibatkan keterampilan matematika dan keterampilan numerik. Temuan lain menunjukkan bahwa anak perempuan memiliki kebiasaan tingkat MA tinggi daripada laki-laki; namun, mereka tidak mengalami MA yang tinggi selama pembelajaran konten matematika atau tes konten matematika (Goetz et al., 2013). Zhang et al., (2019) menemukan bahwa hasil MA pada gender tidak ada perbedaan $(\mathrm{Q}=4.62, \mathrm{p}=0.099)$. Perbedaan gender mempengaruhi pola pikir dan psikologi anak dalam belajar matematika, setiap anak memiliki dorongan yang berbeda dalam menghadapi matematika. Laporan pada perbedaan gender membahas keyakinan seperti faktor non-kognitif pusat dalam menjelaskan hasil gender dalam matematika dan sains domain internasional (Parker et al., 2018). Terlepas dari kenyataan bahwa masingmasing gender memiliki kapasitas math anxiety dengan tingkat yang hampir sama dan hasil sebanding pada tes matematika, ditemukan perbedaan antara anak laki-laki dan perempuan mengenai korelasi antara math anxiety dan kinerja matematika di kedua kelas, korelasi ini signifikan dan negatif untuk anak perempuan tetapi tidak untuk anak laki-laki. Tingkat math anxiety yang lebih tinggi adalah prediktor negatif kinerja matematika untuk anak perempuan saja. Analisis yang membahas pertanyaan jika math anxiety memoderasi efek gender dan nilai serta interaksi gender berdasarkan nilai pada kinerja matematika menunjukkan bahwa math anxiety secara signifikan dimoderasi (Van Mier et al., 2019), dalam lingkup keluarga anxiety bisa tumbuh dalam diri seseorang, hasil penelitian Szczygieł (2020) menunjukkan bahwa math anxiety pada ayah (tetapi bukan ibu dan guru) dikaitkan dengan math anxiety pada anak perempuan, math anxiety pada ibu dan guru (tetapi bukan ayah) menjelaskan tingkat pencapaian matematika pada anak kelas tiga. Hasil penelitian menunjukkan pentingnya orang dewasa dalam membentuk math anxiety dan prestasi matematika peserta didik, tetapi hubungan ini bervariasi tergantung pada gender dan tahun kelas. Hasil yang diperoleh umumnya menunjukkan bahwa math anxiety orang dewasa bukanlah sumber math anxiety anak-anak, tetapi dapat dianggap sebagai sumber prestasi matematika yang rendah di antara anakanak di kelas akhir pendidikan sekolah awal, perlu menerapkan strategi motivasi yang berbeda untuk mengatasi math anxiety, yang tergantung pada gender peserta didik (Milovanović, 2020).

Tinjauan menyeluruh literatur mengungkapkan bahwa kemampuan berpikir divergen dalam pembelajaran 
matematika dapat dipengaruhi oleh math anxiety dan gender, kelemahan berpikir divergen peserta didik sering terlihat pada indikator fleksibilitas, peserta didik hanya menggunakan satu perspektif, pada nyatanya persoalan matematika dapat diselesaikan (Ibnatur Husnul \& Hasanah, 2020; Poves et al., 2020; Faridah \& Ratnaningsih, 2018), kemampuan berpikir divergen dapat ditingkatkan melalui pembelajaran yang merujuk pada proses berpikir kreatif anak dengan melalukan eksplorasi cara belajar dan membantu peserta didik agar terhindar dari rasa cemas dalam belajar matematika, math anxiety memiliki peran yang melibatkan proses berpikir kreatif dan melakukan eksplorasi hal-hal lain, namun math anxiety dapat tumbuh pula melalui lingkungan yang dihadapi dalam proses pembelajaran berlangsung, gender seorang peserta didik melibatkan bagaimana peserta didik tersebut menghadapi masalah matematika dan menerima motivasi dalam belajar, math anxiety pada setiap gender dapat dikontrol dengan memberikan motivasi atau penguatan pada peserta didik, namun bentuk motivasi yang diberikan tergantung pada gender peserta didik, karena gender mempengaruhi cara pandang dalam pembelajaran matematika. Menurut basis bukti literatur, kemampuan berpikir divergen dapat dipengaruhi oleh math anxiety dan gender. Dapat disimpulkan, berdasarkan bukti saat ini, kemampuan berpikir divergen dapat dilatih dengan menumbuhkan minat dalam berpikir kreatif, mengurangi math anxiety pada peserta didik dan pemberian motivasi pada peserta didik sesuai dengan gender.
Dalam tinjauan literatur saat ini, keterbatasan besar adalah kebutuhan akan meningkatkan kemampuan berpikir divergen dalam pembelajaran matematika dan perlu diketahui bahwa jika math anxiety memiliki peran dalam berpikir divergen, dan gender mempengaruhi hasil akhir dalam matematika, dikatakan bahwa anak laki-laki melebihi jumlah perempuan dalam hal pemikiran divergen (pikirkan cara baru untuk mendapatkan jawabannya), prestasi matematika peserta didik dan keterampilan berpikir divergen (Unal \& Demir, 2009) dan ditemukan anak perempuan mempunyai tingkat math anxiety lebih tinggi daripada laki-laki ketika berhadapan dengan tugas-tugas yang melibatkan keterampilan matematika dan keterampilan numerik (Devine et al., 2012; Goetz et al., 2013; Maloney et al., 2021; Van Mier et al., 2019), dan fakta lainnya adalah masingmasing gender memiliki tingkat kecemasan matematika dengan tingkat kurang lebih sama dan hasil yang sebanding pada matematika (Zhang et al., 2019).

\section{KESIMPULAN}

Kemampuan berpikir divergen peserta didik pada pelajaran matematika tersebar pada beberapa indikator, namun pada flexibility dalam berpikir perlu ditingkatkan dengan merancang pemikiran peserta didik pada proses pembelajaran matematika agar dapat berpikir secara meluas dan kreatif serta mengontrol math anxiety peserta didik dalam belajar, math anxiety yang terjadi pada diri peserta didik menjadi sebuah jembatan dalam proses berpikir divergen dalam matematika, math anxiety dapat 
berpengaruh dalam pembelajaran matematika karena setiap individu memiliki tingkat kecemasan yang berbeda, dan math anxiety dapat dipengaruhi oleh lingkungan, math anxiety pada orang dewasa bukanlah sumber math anxiety peserta didik, tetapi dapat dianggap sebagai sumber dari hasil prestasi matematika yang rendah di antara anak-anak di kelas akhir pendidikan sekolah awal (Szczygieł, 2020), dan perempuan memiliki tingkat math anxiety yang lebih tingi daripada laki-laki. Gender berpengaruh dalam pembelajaran matematika karena perempuan dan lakilaki mengontrol hasil pembelajaran matematika dengan kecakapan yang dimiliki oleh masing-masing individu dan motivasi yang diberikan sesuai dengan gender.

\section{DAFTAR PUSTAKA}

Ashcraft, M. H. (2002). Math anxiety: personal, educational, and cognitive consequences. Curr. Direct. Psychol. Sci. 11, 181-185 doi: 10.1111/1467-8721.00196

Beilock, S. L., and Willingham, D. T. (2014). Ask the cognitive scientistmath anxiety: can teachers help students reduce it. Am. Educ. 38, $28-43$.

Brandon,P.,Newton,B.J., and Hammond,O.W. (1985). The Superiority of Girls over Boys in Mathematics Achievment in Hawaii. Paper presented at annual meeting of American Educational Research Association

Devine, A., Fawcett, K., Szücs, D., \& Dowker, A. (2012). Math Anxiety (3). 1-9
Faridah, N.S and Ratnaningsih N. (2019). Analisis Kemampuan Berpikir Divergen Peserta didik Dalam Menyelesaikan Masalah Open Ended. Prosiding Seminar Nasional \& Call For Papers at Program Studi Magister Pendidikan Matematika Universitas Siliwangi, 438-443 ISBN: 978-602-9250-39-8

Fauziah, M., Marmoah, S., Murwaningsih, T., \& Saddhono, K. (2020). Profile of divergent thinking ability of elementary school student in thematic learning. Elementary Education Online, 19(2), 624-640. https://doi.org/10.17051/ilkonline.20 20.693109

Goetz, T., Bieg, M., Ludtke, O., Pekrun, R., and Hall, N. C. (2013). Do girlsreally experience more anxiety in mathematics? Psychol. Sci. 24, 2079-2087.

doi: $10.1177 / 0956797613486989$

Guilford, J.P. (1956). Fundamental Statistic in Psychology and Education. 3rd Ed. New York: McGraw-Hill Book Company, Inc

Hija, Park. (2004). The Effects Of Divergent Production Activities With Math Inquiry And Think Aloud Of Students With Math Difficulty. A Dissertation: Educational Psychology. Texas A\&M University

Ho, H. Z., Senturk,D., Lam, A.G., Zimmer, J.M., Hong, S., andOkamoto, Y., et al. (2000). The affective and cognitive dimensions of math anxiety: a cross-national study. J. Res. Math. Edu. 31, 362379. doi: $10.2307 / 749811$

Ibnatur Husnul, N. R., \& Hasanah, Y. M. (2020). Students' Divergent Thinking Ability in Finishing Economics Mathematical Test Using CEM-Learning (C-Learning, ELearning, M-Learning) at 
Universitas Pamulang. Daya Matematis: Jurnal Inovasi Pendidikan Matematika, 7(3), 283. https://doi.org/10.26858/jds.v7i3.118 73

Kadum, S. (2019). Divergentno mišljenje $\mathrm{u}$ procesu suvremenoga odgoja i obrazovanja. Metodički Ogledi, 26(1), 81-98. https://doi.org/10.21464/mo.26.1.7

Keitel, C. (1998). Social Justice and Mathematics Education Gender, Class, Ethnicity and the Politics of Schooling. Berlin: Freie Universität Berlin

Maloney, E. A., Waechter, S., Risko, E. F., and Fugelsang, J. A. (2012). Reducing the sex difference in math anxiety: the role of spatial processing ability. Learn. Indiv. Diff. 22, 380384.

doi:

10.1016/j.lindif.2012.01.001

Milovanović, I. (2020). Math anxiety, math achievement and math motivation in high school students: Gender effects. Croatian Journal of Education, 22(1), 175-206. https://doi.org/10.15516/cje.v22i1.33 72

Parker, P. D., Van Zanden, B., \& Parker, R. B. (2018). Girls get smart, boys get smug: Historical changes in gender differences in math, literacy, and academic social comparison and achievement. Learning and Instruction, 54, 125-137. https://doi.org/10.1016/j.learninstruc. 2017.09.00

Poves, G. A. B., Chávez, D. A., Diaz, H. H. A., \& Blácido, I. R. (2020). Divergent thinking of students in the field of education at a university in Lima. International Journal of Early Childhood Special Education, 12(1), 452-458.

https://doi.org/10.9756/INT-

\section{JECSE/V12I1.201025}

Pujiastuti, E., Suyitno, A., \& Sugiman. (2020). Using of divergent problems based on teacher scaffolding levels to grow of advanced mathematical thinking of senior high school students. Journal of Physics: Conference Series, 1567(2). https://doi.org/10.1088/17426596/1567/2/022093

Sosa, R. (2018). El pensamiento divergente en las organizaciones. Recuperado el 12 de diciembre del 2019 https://lideresmexicanos.com/noticia s/el-valor-del-pensamientodivergente-en-las-organizaciones/

Sriyanto. (2007). Strategi Sukses menguasai Matematika. Jakarta: PT. Buku Kita

Susento. (2006). Mekanisme Interaksi Antara Pengalaman KulturalMatematis, Proses Kognitif, dan Topangan dalam Reivensi Terbimbing. Disertasi. Surabaya: Unesa

Szczygieł, M. (2020). When does math anxiety in parents and teachers predict math anxiety and math achievement in elementary school children? The role of gender and grade year. Social Psychology of Education, 23(4), 1023-1054. https://doi.org/10.1007/s11218-02009570-2

Unal, H., \& Demir, I. (2009). Divergent thinking and mathematics achievement in Turkey: Findings from the programme for international student achievement (PISA-2003). Procedia - Social and Behavioral Sciences, $\quad 1(1)$, 1767-1770. https://doi.org/10.1016/j.sbspro.2009 .01 .313

Van Mier, H. I., Schleepen, T. M. J., \& 
Van den Berg, F. C. G. (2019).

Gender differences regarding the impact of math anxiety on arithmetic performance in second and fourth graders. Frontiers in Psychology, 9(JAN), 1-13. https://doi.org/10.3389/fpsyg.2018.0 2690

Zhang, J., Zhao, N., \& Kong, Q. P. (2019). The relationship between math anxiety and math performance: a meta-analytic investigation. Frontiers in Psychology, 10(AUG), $1-17$.

https://doi.org/10.3389/fpsyg.2019.0 1613 